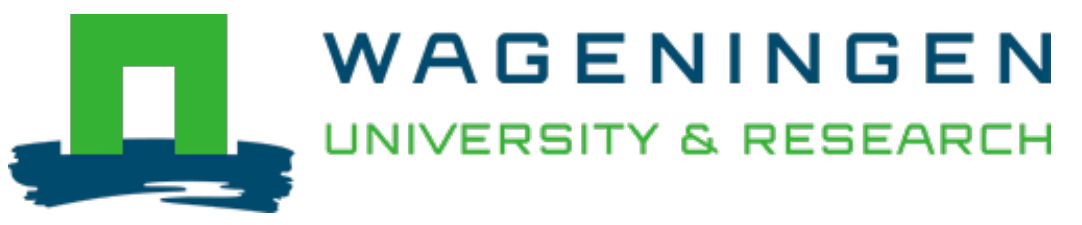

\title{
Healthy Snacks from Mom? An Agent-Based Model of Snackification in Three Countries
}

\author{
Advances in Social Simulation - Proceedings of the 15th Social Simulation Conference, 2019 \\ Hofstede, Gert Jan; Franco, Eduardo; Damen, Femke; Fogliano, Vincenzo \\ https://doi.org/10.1007/978-3-030-61503-1_41
}

This article is made publicly available in the institutional repository of Wageningen University and Research, under the terms of article $25 \mathrm{fa}$ of the Dutch Copyright Act, also known as the Amendment Taverne. This has been done with explicit consent by the author.

Article 25 fa states that the author of a short scientific work funded either wholly or partially by Dutch public funds is entitled to make that work publicly available for no consideration following a reasonable period of time after the work was first published, provided that clear reference is made to the source of the first publication of the work.

This publication is distributed under The Association of Universities in the Netherlands (VSNU) 'Article $25 \mathrm{fa}$ implementation' project. In this project research outputs of researchers employed by Dutch Universities that comply with the legal requirements of Article $25 \mathrm{fa}$ of the Dutch Copyright Act are distributed online and free of cost or other barriers in institutional repositories. Research outputs are distributed six months after their first online publication in the original published version and with proper attribution to the source of the original publication.

You are permitted to download and use the publication for personal purposes. All rights remain with the author(s) and / or copyright owner(s) of this work. Any use of the publication or parts of it other than authorised under article $25 \mathrm{fa}$ of the Dutch Copyright act is prohibited. Wageningen University \& Research and the author(s) of this publication shall not be held responsible or liable for any damages resulting from your (re)use of this publication.

For questions regarding the public availability of this article please contact openscience.library@wur.nl 


\title{
Chapter 41 \\ Healthy Snacks from Mom? \\ An Agent-Based Model of Snackification in Three Countries
}

\author{
Gert Jan Hofstede ${ }^{D}$, Eduardo Franco $(D)$, Femke Damen (D), \\ and Vincenzo Fogliano
}

\begin{abstract}
An agent-based model SNACKMOMS was created to understand the implications and consequences of interventions that may change the dietary habits of children. It targets the giving of snacks to children aged 2-7 by their mother and how the snacking pattern is modified by the examples set at children parties. The model acknowledges individual-level, group-level and cultural-level variables. Dynamics of conformity at parties depending on social status are taken into account in Dutch, Indonesian and Italian culture, backed up by survey and interview data. The main model output is healthy versus unhealthy snacking, and it shows how this might change as a function of the mothers' characteristics and of external intervention. Results suggest differences in the effectiveness of the intervention across countries whether interventions target children's preferences versus mothers' health orientation. This indicates that the same approach might not be equally effective across societies.
\end{abstract}

Keywords Healthy food - Snackification · Mothers • Pre-school children • Agent-based model $\cdot$ National culture $\cdot$ Marketing $\cdot$ Intervention

\footnotetext{
G. J. Hofstede $(\bowtie)$

Information Technology Group, Social Sciences, Wageningen University, Wageningen, Netherlands

e-mail: gertjan.hofstede@wur.nl

UARM, North-West University, Potchefstroom, South Africa

E. Franco

Computer and Digital Systems Engineering, University of São Paulo, São Paulo, Brazil e-mail: eduardo.franco@gmail.com

Bioengineering and Operational Research, Sapienza University of Rome, Rome, Italy

F. Damen · V. Fogliano

Food Quality \& Design Group, Wageningen University, Agrotechnology \& Food Sciences, Wageningen, Netherlands

e-mail: femke.brouwer-damen@wur.nl

V. Fogliano

e-mail: vincenzo.fogliano@wur.nl
}

(C) The Author(s), under exclusive license to Springer Nature Switzerland AG 2021

P. Ahrweiler and M. Neumann (eds.), Advances in Social Simulation,

Springer Proceedings in Complexity,

https://doi.org/10.1007/978-3-030-61503-1_41 


\section{Introduction}

Childhood obesity is a major problem worldwide. Rates increased over the last decades [12]. One factor contributing to childhood obesity is 'snackification'. The intake of calories outside meals is increasing all around the world, and among children the intake of energy-dense snacks is highly prevalent $[7,10]$. Childhood unhealthy dietary behaviour, as well as the prevalence of overweight, could track into adulthood [15] which results in a higher risk for health problems, also later in life [13].

Parents are mainly responsible for the development of their young child's dietary behaviour [17] These are in most cases the mothers [14]. Therefore, mothers play an important role in the development of children's dietary behaviour [9]. Mothers from different countries experience different value conflicts between healthy and desired snacks. $[1,3,11]$.

Child obesity development differs across countries and is on the decrease in some countries [16]. Nutrition policies and educational campaigns are clearly having some effects; results differ in across countries. This raises questions about cross-cultural differences in the mechanisms involved in mothers' snack choice.

Cultural values have a deep influence on all possible behaviours in society, especially ones around relationally important and/or taboo issues [4, 8]. The causes and mechanisms of snack-giving, as well as the ways to influence it in a desirable direction, thus also likely differ across cultures.

Snack choices of mothers with young children were investigated in a recent study [2]. Frequent snacks were fruits, cookies, and candy. Considerations most used were snack healthiness and child's preference. Higher educated mothers, as well as firstchild mothers, showed more health-conscious behaviour.

Another study investigated which considerations play a role in the snack providing across countries [1]. Countries included in this study were the Netherlands (NL), Indonesia (ID) and Italy (IT); these three were chosen based on their differences on Hofstede's dimensions of national culture. Mothers from different countries revealed different considerations when choosing snacks for their young children, as presented in Table 41.1 .

The dietary pattern of the children is subject to many influences that can be towards healthier or unhealthier habits. For example, many public campaigns have been launched in the last years to make mothers conscious about the benefits of healthier habits with their children; at the same time, companies are introducing new unhealthy snacks, launched with big mass advertisement campaigns targeting young children. Regulatory agencies ask food companies to improve the nutritional quality of their products. When they do this, they often face a decrease in sales because a consistent part of consumers is not ready to accept the reformulated healthier products.

In this framework, it would be useful to understand which are the interventions which might induce (or not) a shift in the dietary habits of a specific group of consumers. For this, we carried out a bottom-up modelling study in which we hypothesize mechanism of snack-giving that are compatible with the data presented 
Table 41.1 Values arising during snack selection of mothers per country, adapted from [1]. Values mentioned by $>$ half of the mothers in a country are in boldface

\begin{tabular}{l|l|l|l|l}
\hline \multirow{2}{*}{ Key themes } & Values & $\begin{array}{l}\mathrm{NL} \\
(\mathrm{n}=17)\end{array}$ & $\begin{array}{l}\mathrm{ID} \\
(\mathrm{n}=17)\end{array}$ & $\begin{array}{l}\mathrm{IT} \\
(\mathrm{n}=17)\end{array}$ \\
\hline \multirow{4}{*}{ Health-related } & Healthiness & 17 & 15 & 14 \\
\cline { 2 - 5 } & Balance/Moderation & 15 & 4 & 7 \\
\cline { 2 - 5 } & Natural/Fresh/Organic & 4 & 5 & 8 \\
\cline { 2 - 5 } & Portion size & 10 & 9 & 8 \\
\cline { 2 - 5 } & Variety & 9 & 4 & 9 \\
\hline \multirow{5}{*}{ Child-related } & Child's preference & 12 & 16 & 17 \\
\cline { 2 - 5 } & Freedom for child/Not forcing to eat & 3 & 2 & 6 \\
\cline { 2 - 5 } & Health status of child & 6 & 8 & 6 \\
\cline { 2 - 5 } & Development of taste & 2 & 2 & 1 \\
\cline { 2 - 5 } & Prevent hunger & 4 & 5 & 1 \\
\hline \multirow{5}{*}{ Product-related } & Convenience & 14 & 10 & 7 \\
\cline { 2 - 5 } & Making own food & 0 & 6 & 4 \\
\cline { 2 - 5 } & Religion & 0 & 10 & 0 \\
\cline { 2 - 5 } & Price & 9 & 6 & 5 \\
\cline { 2 - 5 } & Brand & 1 & 0 & 8 \\
\cline { 2 - 5 } & Sustainability & 6 & 0 & 1 \\
\cline { 2 - 5 } & Packaging & 4 & 3 & 5 \\
\hline
\end{tabular}

above, and with the cross-cultural differences found in the studies by Hofstede et al. [8]. In our model we take a bottom-up approach of modelling children's parties and social influence by neighbours. We also take a cross-cultural perspective, using society-level cultural parameters, to parameterise our model. Using these elements, we 'grow' the system in which snack types are being selected and snacks are being provided.

We decided to model an issue that we deemed of central importance: the providing of snacks to young children (aged 2-7) by their mothers. From the empirical study in [1], we gather that both individual-level factors, shared cultural factors, and social contagion play a role. We therefore chose the technique of agent-based modelling, since it allows to 'grow' a real-world system in its context while staying close to that context [6]. Specifically, it allows to include individual variables, model-wide parameters, social status and everyday proximity. The result is the SNACKMOMS model presented here.

The main hypothesis of the proposed model is that the complex psychological and social factors highlighted above can be grouped in two main factors. An individual parameter named "mother health orientation" and a cultural parameter named 
Table 41.2 Model's parameters related to national characteristics

\begin{tabular}{|c|c|c|c|c|c|}
\hline \multirow[t]{2}{*}{ Parameter name } & \multirow[t]{2}{*}{ Range } & \multicolumn{3}{|c|}{ Default value } & \multirow[t]{2}{*}{ Function } \\
\hline & & NL & ID & IT & \\
\hline Mother-average-leniency & $0-1$ & 0.15 & 0.4 & 0.25 & $\begin{array}{l}\text { Mean value for } \\
\text { random normal } \\
\text { distribution used } \\
\text { to setup mother's } \\
\text { leniency. Mean } \\
\text { value for random } \\
\text { normal } \\
\text { distribution used } \\
\text { to setup mother's } \\
\text { leniency }\end{array}$ \\
\hline Mother-average-health-orientation & $0-1$ & 0.75 & 0.50 & 0.60 & $\begin{array}{l}\text { Mean for random } \\
\text { normal } \\
\text { distribution of } \\
\text { mother's health } \\
\text { orientation }\end{array}$ \\
\hline Mother-average-social-status & $0-1$ & 0.70 & 0.30 & 0.50 & $\begin{array}{l}\text { Mean value for } \\
\text { random normal } \\
\text { distribu-tion of } \\
\text { mother's social } \\
\text { status }\end{array}$ \\
\hline Value-conflict-decay-time & $1-500$ & 75 & 40 & 5 & $\begin{array}{l}\text { Time span that the } \\
\text { value conflict } \\
\text { de-creases to } \\
\text { zero. High values } \\
\text { cause moth-ers to } \\
\text { dissipate value } \\
\text { conflict fast }\end{array}$ \\
\hline Health-orientation-stability & $1-500$ & 200 & 400 & 70 & $\begin{array}{l}\text { Period in which } \\
\text { mothers change } \\
\text { their health } \\
\text { orientation trying } \\
\text { to minimize } \\
\text { future value } \\
\text { conflict }\end{array}$ \\
\hline
\end{tabular}

"mother leniency" are assigned. The former is attitudinal. It differs between individual mothers based on a population average. The latter is a group-level characteristic of a certain mother group based on literature evidence and the findings of our previous studies.

The mother health orientation can be modified by the interaction with their children and with the other mothers. To allow for social pressure, SNACKMOMS simulates interaction by the attendance of kids and mothers at children's parties where a certain type of snacks is offered in a very public context.

Agent-based models such as the one created here can have many possible aims [5]. The aim of this paper is to better explain and understand the dynamics of snack 
Table 41.3 Model's parameters related to the external interventions

\begin{tabular}{l|c|c|l|l|l}
\hline \multirow{2}{*}{ Parameter name } & \multirow{2}{*}{ Range } & \multicolumn{2}{|l|}{ Default value } & Function \\
\cline { 3 - 5 } & & NL & ID & IT & \\
\hline Intervention-type & \multicolumn{2}{|c|}{ N/A } & $\begin{array}{l}\text { Defines what will be influenced } \\
\text { (mother leniency, mother health } \\
\text { orientation, or child healthy } \\
\text { preference) }\end{array}$ \\
\hline Intervention-efficacy & $-1-1$ & -0.50 & $\begin{array}{l}\text { Impact value in attribute chosen for } \\
\text { the intervention-type. Will temporarily } \\
\text { change the agent's selected attribute }\end{array}$ \\
\hline External-stimulus-decay & $0-100$ & 35 & $\begin{array}{l}\text { Decay time for the effect of } \\
\text { intervention-effect } \text { on the agents. } \\
\text { Higher values mean the stimulus will } \\
\text { last for longer }\end{array}$ \\
\hline Intervention-coverage & $0-1$ & 0.10 & $\begin{array}{l}\text { Percentage of the agents' population } \\
\text { affected by the external intervention }\end{array}$ \\
\hline
\end{tabular}

providing by mothers to their young children across cultures, and its effects on the child's dietary pattern. The purpose is not to predict these effects; merely to understand them better, as well as offering a boundary object for discussing system structure with stakeholders such as marketers and health professionals. In addition, we aim to understand the potential effect of outside interventions such as media campaigns, specific policy enforcement or nutritional labelling. The current paper presents the model, model analysis, and preliminary results.

\section{The Model: SNACKMOMS}

\section{Description}

For reasons of space, the following description is incomplete; more details can be obtained from the authors. SNACKMOMS was built with NetLogo [18], and it will be placed on OpenABM. The model user interface is shown in Fig. 41.1.

The model "world" is represented as a square with $20 \times 20$ patches, and it contains three types of agents: child, mother, and the environment (i.e., patches). On each patch, there is a household composed of a mother and a set of children (ranging from 1 to 3). The mother is represented as a face, which illustrates some of her characteristics: leniency (happy—high leniency, straight—average leniency, and sad—low leniency), social status (the bigger the icon, the higher the social status), health experience (colour gradient between green and red, representing healthy and unhealthy snacks giving habit respectively), and number of children (small white number on the bottom right of the mother's icon). 

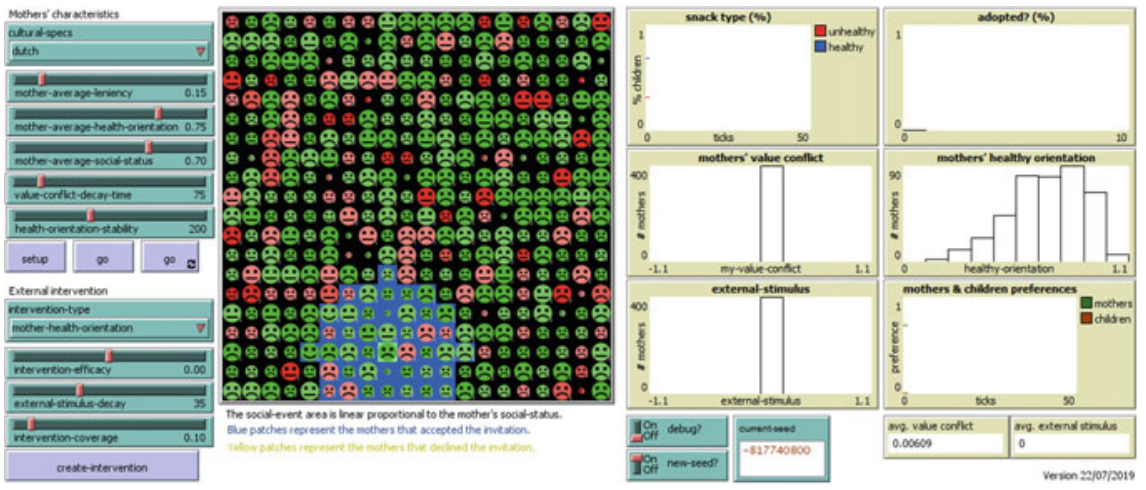

Fig. 41.1 The model interface at $t=0$

Further, the model contains nine parameters that are located on the left side of Fig. 41.1 and listed in Tables 41.2 and 41.3. These parameters are mainly used to setup the model's initial conditions. The parameters in Table 41.2 show the default values which were defined based on the national specific characteristics.

These defaults are based on our interpretation, in terms of national culture dimensions proposed by Hofstede et al. [8], of the mother's snack giving behaviour, and on Table 41.1. The salient dimensions of culture concepts that were used in the model design are: Individualism, can be defined as a preference for a loosely-knit social framework in which individuals are expected to take care of only themselves and their immediate families (scores in Hofstede et al. [8]: Ind: 14,Ita: 76; Nl: 79); Power Distance, expresses the degree to which the less powerful members of a society accept and expect that power is distributed unequally (Ind: 78, Ita: 50, N1: 38); and

Table 41.4 Model main state variables and their descriptions

\begin{tabular}{l|l}
\hline Variable name & Description \\
\hline My-value-conflict & $\begin{array}{l}\text { Can change depending on whether the mothers give snacks that everyone } \\
\text { around them give, or not (a floating number between 1 and 0) }\end{array}$ \\
\hline Adopted? & $\begin{array}{l}\text { Indicates whether the mother or child was influenced by the external } \\
\text { intervention or not }\end{array}$ \\
\hline Adoption-length & Indicates for how long the mother or child is being stimulated \\
\hline External-stimulus & $\begin{array}{l}\text { Stores the stimulus accrued by the mother or child from an external } \\
\text { intervention }\end{array}$ \\
\hline Behaviour & $\begin{array}{l}\text { Randomly defined variable that represents how the child is behaving } \\
\text { (higher numbers indicate "good" behaviour) }\end{array}$ \\
\hline Memory & A list of child's pasts five snack experiences \\
\hline Current-desire & $\begin{array}{l}\text { Child desired snack orientation represented by a float number between "1" } \\
\text { and "0" (a higher number indicates healthy snack) }\end{array}$ \\
\hline
\end{tabular}


Table 41.5 Model plots and their descriptions

\begin{tabular}{l|l}
\hline Plot & Description \\
\hline Snack type (\%) & $\begin{array}{l}\text { The relative number of healthy and unhealthy snack giving } \\
\text { decisions taken over time }\end{array}$ \\
\hline Adopted? (\%) & $\begin{array}{l}\text { The relative number of mothers or children that adopted the } \\
\text { 'advertisement campaign' over time }\end{array}$ \\
\hline Mothers' value conflict & A histogram of the mothers experienced value conflict \\
\hline Mothers' healthy orientation & A histogram of the mothers' healthy orientation \\
\hline External-stimulus & $\begin{array}{l}\text { Shows the distribution of the external stimulus suffered by } \\
\text { each agent (mothers or children) where it is possible to see } \\
\text { how it decays over time }\end{array}$ \\
\hline Mothers \& children preferences & $\begin{array}{l}\text { Shows the mothers' intentions and children's desires toward } \\
\text { healthy snack. This is not the final decision, which is shown } \\
\text { throw the snack type (\%) plot }\end{array}$ \\
\hline
\end{tabular}

Uncertainty Avoidance, expresses the degree to which the members of a society feel uncomfortable with uncertainty and ambiguity (Ind: 48; Ita: 75; Nl: 53).

Note that in the model 'leniency' means the mother's tendency to follow the child's wish. We assume mother-average-leniency to be higher when complementarity, not independence is the essence of the mother-child relation; this is the case in Indonesia, the only collectivistic country in our set. We assume the reverse for mother-average-health-orientation; this is supported by Table 41.1. We assume mother-average-social-status, the capacity of an individual to exert social influence, to be inversely related to Power Distance. Value-conflict-decay-time, as a measure of independence, we assume to be proportional with Individualism. We finally assume health-orientation-stability, as a measure of tolerance of potential value conflict, to be inversely related with Uncertainty Avoidance.

Still on the user interface, there is a set of plots where it is possible to check the dynamics involved during the snack giving context. The plots are shown on the right side of the interface and a brief description of each of them is provided on Table 41.5.

\section{Decision-making Process}

Every time step ("tick"), each mother interacts with her children and other mothers (the number of mothers interacting depends on the current social dynamics occurring in tick $t$ ) to make her decisions on which snack type to give (healthy or unhealthy).

The decision-making process is illustrated in Fig. 41.2. First, the mother checks whether she is attending a social event or not. Next, each child formulates his/her snack type desire (healthy or unhealthy). Finally, mothers decide considering their intention and their children's desires, weighted by their leniency and children's behaviour. When a child misbehaves (i.e., has a low value for the variable behaviour 


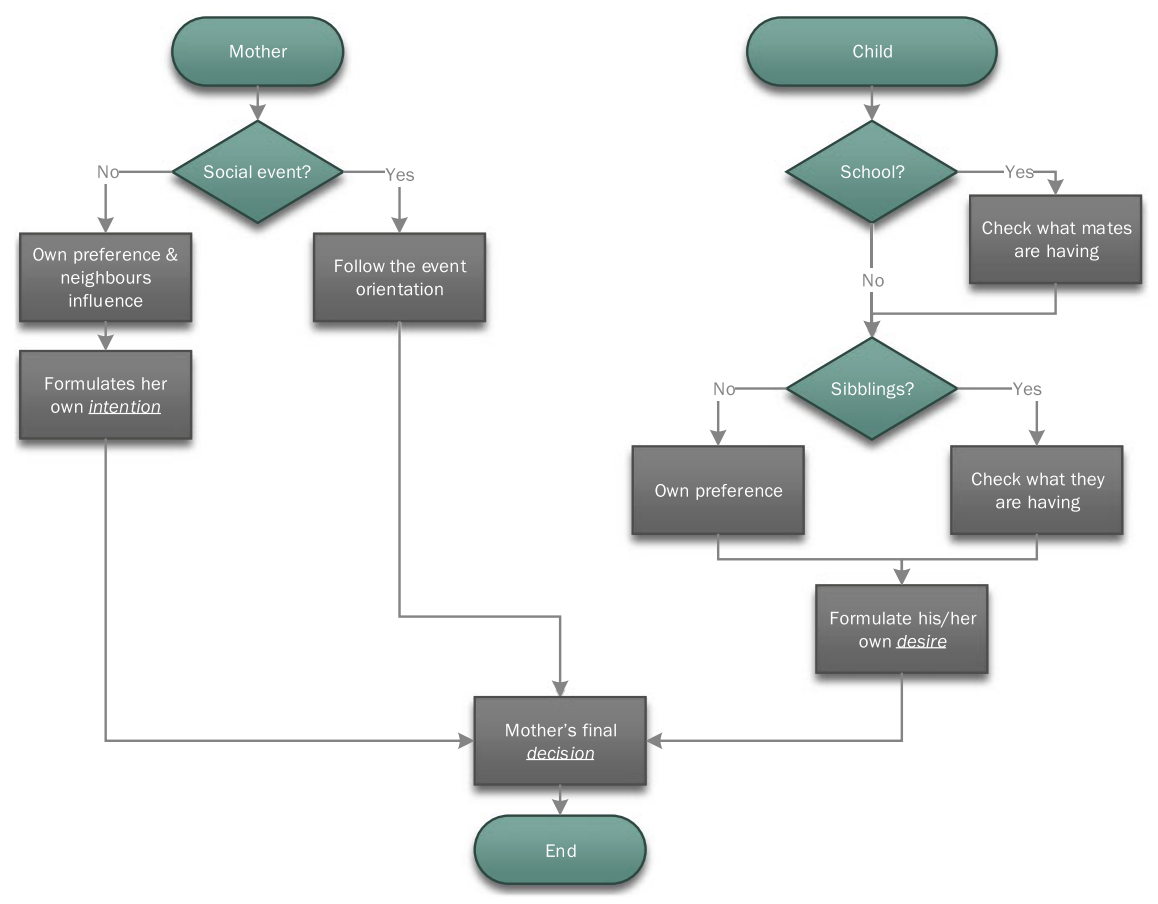

Fig. 41.2 Mother's and child's decision-making process

at tick $t$ ) and his/her mother is indulgent, the mother tends to follow the child's desire. On the other hand, if the mother is not indulgent, she tends to follow her intention despite the child's behaviour. Mothers can change their health orientation and leniency by interacting during social events.

\section{Social Dynamics}

In the model, every tick stands for one week. Within each tick, children and mothers formulate their snack desires and intention based on their intrinsic characteristics and the influences received from the environment (children are influenced by schoolmates and siblings, and mothers are influenced by their children and other mothers).

Every tick, a randomly chosen mother (at centre in Fig. 41.4) hosts a party and invites her neighbours for celebrating. The higher the social status of the inviting mother, the more neighbours will be invited.

Every party has a unique snack orientation, which is based on the past snacking experience (memory) of the host mother (green means healthy, red unhealthy). During a social event, each mother can experience a value conflict. This occurs when a snack offered by the host mother during a party is against her natural health orientation. 


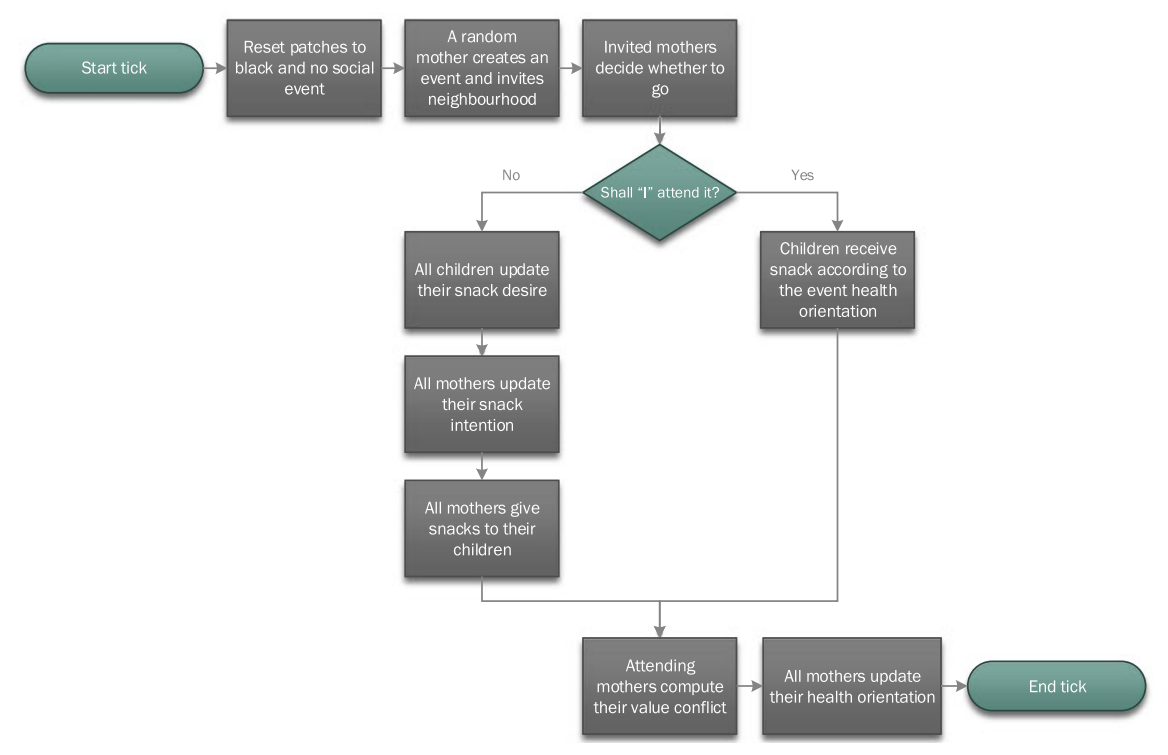

Fig. 41.3 Flowchart of actions performed during one time step ("tick")

After being invited, a mother chooses to accept (blue patches in Fig. 41.4) or decline (yellow patches in Fig. 41.4). The invited decides based on the difference in social status with the host, the host's health orientation, and the invited mother's value conflict.

After experiencing a value conflict, the mother will try to minimize her conflict applying two mechanisms: declining invitations for parties hosted by mothers with different health orientation, or accepting but adapting her health orientation.

Figure 41.3 shows a flowchart detailing how the social dynamics was implemented.

When an external intervention is created, a randomly set of mothers are impacted (according to the intervention-coverage parameter), and they are represented by purple background (Fig. 41.4). During a social event, mothers interact, and the ones that adopted the intervention and are under the influence defined by the interventionefficacy parameter spread the message of the external intervention to the other susceptible mothers according to their social status (i.e., purple background).

\section{Model Analysis}

A one-at-a-time sensitivity analysis was conducted with a different seed for each run. To save space, the results are omitted. They can be obtained from the authors. 


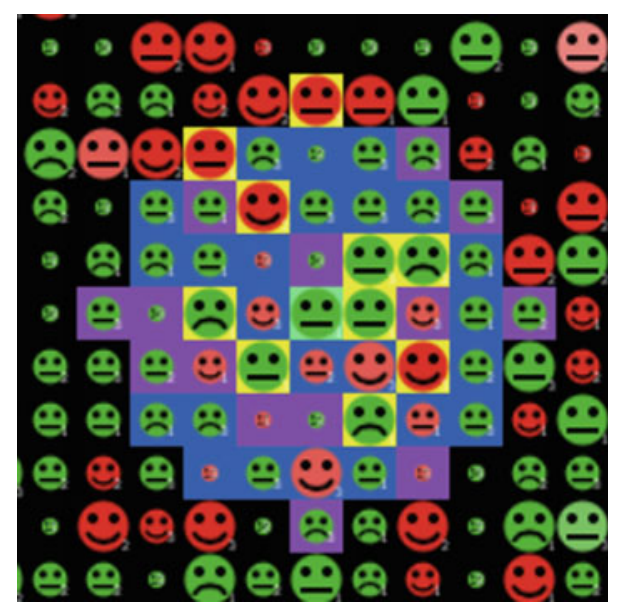

Fig. 41.4 Graphical representation of the model's social dynamics
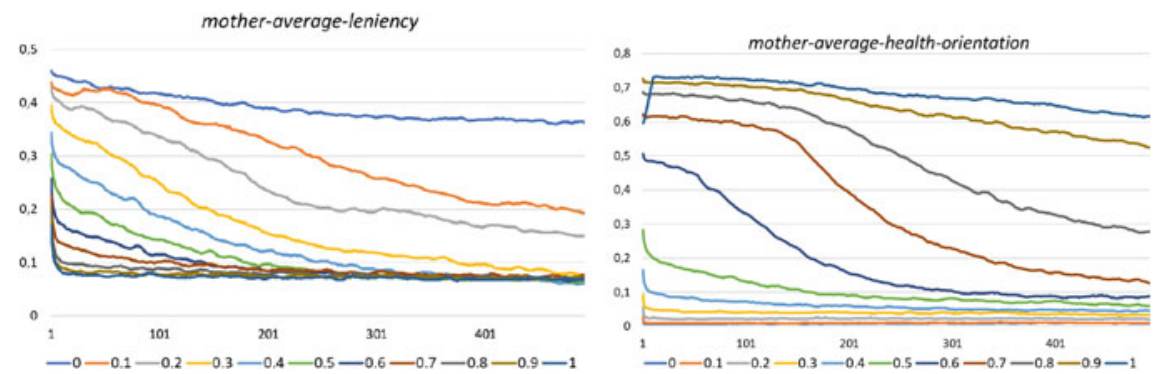

Fig. 41.5 Average values of snack giving patterns over time

Figure 41.5 shows that indulgent mothers (left-hand plot) tend to be less strict to their health orientation and provide their children with an unhealthy snack, and higher values of health-orientation lead to healthier habits (right-hand plot).

\section{Model Results}

Based on the output obtained from the sensitivity analysis and the mothers' characteristics gathered from [1], default values for the model for the three countries were defined (see Table 41.2). Then, we ran experiments to evaluate how mothers from the three countries would respond to external interventions.

The experiment was set to introduce an exogenous intervention at $t=100$ ticks, using the default values presented in Table 41.2. Each country setting ran for two 


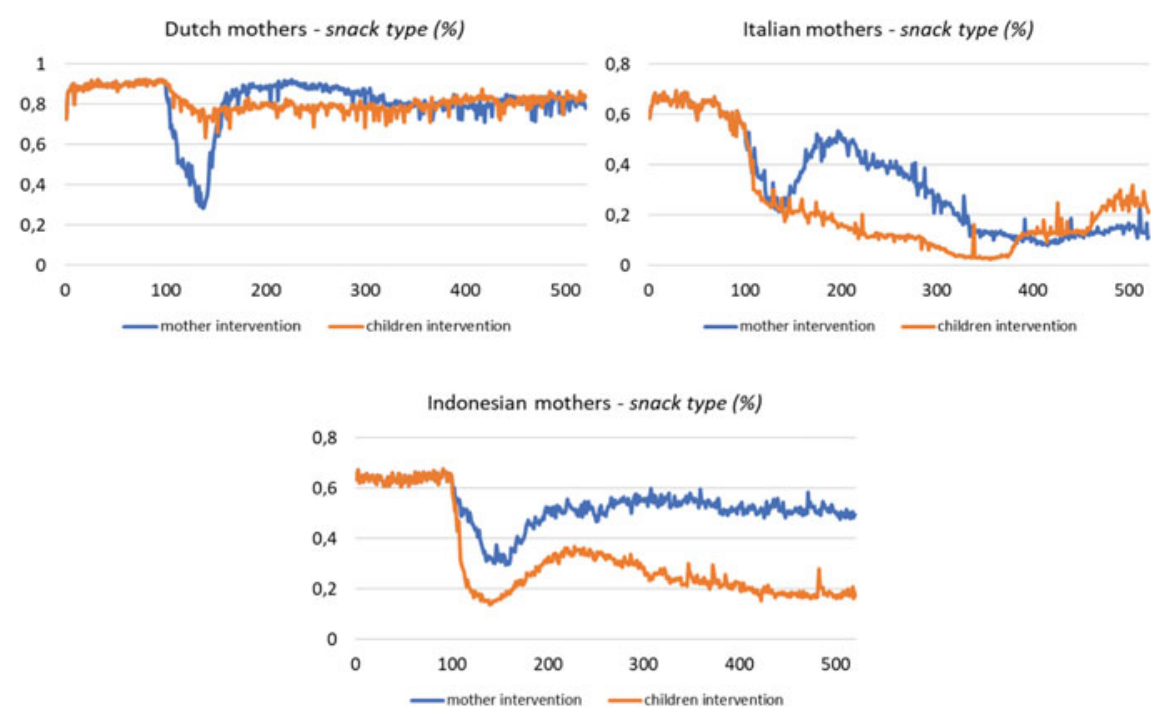

Fig. 41.6 Mothers reactions due to external intervention

runs to explore the effects of the two interventions type child-healthy-preference and mother-health-orientation, and the results are shown in Fig. 41.6.

The model shows Dutch mothers to be more resilient to external influence. Due to their parameters (Table 41.2), mothers tend to dissipate the external influence faster than changing their mindset. This behaviour can be explained by the mothers not being indulgent, and thus they are less influenced by their children.

Italian mothers change their mindset quickly (low value for health-orientationstability), so when they are stimulated with negative influence, they tend to become unhealthy. Conversely, Indonesian mothers are tight in their health orientation, so they change their mindset slowly. They return to their natural health orientation after the effect of the intervention is gone. However, targeting children can bring an emergent unhealthy pattern, as Indonesian mothers are prone to give in to their children.

\section{Discussion and Conclusion}

Snacking dynamics. The sensitivity analysis shows huge variability of the output, snack healthiness percentage, for many values of the input variables leniency and health-orientation. This means that this is a system that has parts of its parameter space for which the outcome variable, healthiness of snacks provided, is highly unpredictable. That, in turn, makes it potentially possible to nudge that healthiness in the 
desired direction through interventions. Leniency, as a society-wide cultural parameter, is not directly susceptible to interventions. Health-orientation, an individuallevel parameter, could be easier to influence. Our results show that whether it is more effective to target children or mothers would depend on local culture.

Options for interventions. The simulation includes three sets of parameter values that represent Italy, Netherlands, and Indonesia. Their current values are educated guesses. We claim plausibility for these values, but not realism. The exercise does show that the same approach might not be equally effective across societies.

Further research. Validation in country-specific studies would give more confidence. Sociological studies, questionnaire and market surveys can all contribute. Through its variables and parameters, the model suggests what kind of data could be used. The approach taken here can extend to other systems in society that are of public interest, can be affected by policy, and of which the micro-dynamics are reasonably well understood. One can think of snacking at secondary schools, school breakfast, but also sport- and leisure-related behaviours involving children.

Conclusion. SNACKMOMS can provide handles to institutional actors and private companies about interventions, depending on social propensities of the population. An example is the "School fruits" an EU program rolled out in all European countries distributing fruit in the school to encourage healthy snacking. The effectiveness of this intervention targeting millions of children can be very different depending of the societal context. Our simulation shows that a country-tailored approach matching the fruit distribution with educative measures toward children and their families could be more effective.

Acknowledgements The research was carried out thanks to the financial support of "Soremartec Italia Srl" (Alba, Cuneo, Italy). The funder had no role in study design, data collection and analysis, decision to publish or preparation of the manuscript.

\section{References}

1. F.W.M. Damen, G.J. Hofstede, B.L.P.A. Steenbekkers, P. Vitaglione, N. Pellegrini, V. Fogliano, P.A. Luning, Values and value conflicts in snack providing of Dutch, Polish, Indonesian and Italian mothers. Food Res. Int. 115, 554-561 (2019). https://doi.org/10.1016/j.foodres.2018. 09.047

2. F.W.M. Damen, P.A. Luning, V. Fogliano, B.L.P.A. Steenbekkers, What influences mothers' snack choices for their children aged 2-7? Food Qual. Prefer. 74, 10-20 (2019). https://doi. org/10.1016/j.foodqual.2018.12.012

3. F.W.M. Damen, B.L.P.A. Steenbekkers, M.T. Vaal, J.K. de Kampen, V. Fogliano, P.A. Luning, General parenting and mothers' snack giving behaviour to their children aged 2-7. Manuscript Sumbitted for Publication (2020)

4. M. De Mooij, Global Marketing and Advertising: Understanding Cultural Paradoxes (5th ed). SAGE. (2019) 
5. B. Edmonds, C. Le Page, M. Bithell, E. Chattoe-Brown, Different modelling purposes. J. Artif. Soc. Soc. Simul. 22(3). (2019) https://doi.org/10.18564/jasss.3993

6. B. Edmonds, S. Moss, From KISS to KIDS - An 'Anti-simplistic' Modelling Approach. MABS'04: Proceedings of the 2004 International Conference on Multi-Agent and Multi-AgentBased Simulation, 130-144 (2004). https://doi.org/10.1007/978-3-540-32243-6_11

7. D.W. Gevers, S.P. Kremers, N.K. de Vries, P. van Assema, Intake of energy-dense snack foods and drinks among Dutch children aged 7-12 years: how many, how much, when, where and which? Public Health Nutr. 19(1), 83-92 (2016). https://doi.org/10.1017/S1368980015000877

8. G. Hofstede, G.J. Hofstede, M. Minkov, Cultures and Organizations: Software of the Mind (3rd ed). McGraw-Hill Education, (2010)

9. J.E. Holsten, J.A. Deatrick, S. Kumanyika, J. Pinto-Martin, C.W. Compher, Children's food choice process in the home environment. a Qualitative Descriptive Study. Appetite 58(1), 64-73 (2012). https://doi.org/10.1016/j.appet.2011.09.002

10. N. Larson, M. Story, A review of snacking patterns among children and adolescents: what are the implications of snacking for weight status? Childhood Obes. 9(2), 104-115 (2013). https:// doi.org/10.1089/chi.2012.0108

11. R. Moceviciene, A. Zaborskis, Methods to encourage healthy eating in children: Review of current findings. Baltic Journal of Health and Physical Activity, 5(4) (2013).https://doi.org/10. 2478/bjha-2013-0026

12. C.L. Ogden, M.D. Carroll, B.K. Kit, K.M. Flegal, Prevalence of childhood and adult obesity in the United States, 2011-2012. JAMA 311(8), 806 (2014). https://doi.org/10.1001/jama.201 4.732

13. J.J. Reilly, J. Kelly, Long-term impact of overweight and obesity in childhood and adolescence on morbidity and premature mortality in adulthood: systematic review. Int. J. Obes. 35(7), 891-898 (2011). https://doi.org/10.1038/ijo.2010.222

14. R.R. Rosenkranz, D.A. Dzewaltowski, Model of the home food environment pertaining to childhood obesity. Nutr. Rev. 66(3), 123-140 (2008). https://doi.org/10.1111/j.1753-4887.2008.000 17.x

15. A.S. Singh, C. Mulder, J.W.R. Twisk, W. Van Mechelen, M.J.M. Chinapaw, Tracking of childhood overweight into adulthood: a systematic review of the literature. Obes. Rev. 9(5), 474-488 (2008). https://doi.org/10.1111/j.1467-789X.2008.00475.x

16. A. Spinelli, M. Buoncristiano, V.A. Kovacs, Prevalence of severe obesity among primary school children in 21 European Countries. Obes. Facts 12(2), 244-258 (2019). https://doi.org/10.1159/ 000500436

17. M. Tiggemann, J. Lowes, Predictors of maternal control over children's eating behaviour. Appetite 39(1), 1-7 (2002). https://doi.org/10.1006/appe.2002.0487

18. U. Wilensky, NetLogo (6.1.1). Center for Connected Learning and Computer-Based Modeling, Northwestern University, (1999). https://ccl.northwestern.edu/netlogo/ 